\title{
High-temperature heat treatment of hypersonic metallization coatings from pseudoalloy "Fe-Al"
}

\author{
A. N. Grigorchik, E. V. Astrashab ${ }^{\dagger}$, V. A. Kukareko, M. A. Belotserkovsky, A. V. Sosnovsky \\ †astrashabev@mail.ru
}

The Joint Institute of Mechanical Engineering National Academy of Sciences of Belarus, Minsk, 220072, Belarus

\begin{abstract}
The structural-phase state and durometric characteristics of hypersonic metallization coatings made of pseudoalloy "Fe-Al" in the initial state and after heat treatment were investigated. The heat treatment consisted in heating the coating samples to temperatures of $570,620,720,820$ and $920^{\circ} \mathrm{C}$ followed by holding for 5,10 and 20 minutes and air cooling. The phase composition of the "Fe-Al" coating sprayed by hypersonic metallization in the initial state includes $\alpha-\mathrm{Fe}, \mathrm{Al}_{2} \mathrm{Al}_{2} \mathrm{O}_{3}$ and $\mathrm{FeO}$. The hardness of the coating is $220 \mathrm{HV} 10$, and the microhardness of the steel interlayers is $350 \mathrm{HV} 0.025$. It is shown that heat treatment of the coating in the temperature range $570-920^{\circ} \mathrm{C}$ and holding time of $5-20$ minutes leads to the formation of strengthening intermetallic phases $\mathrm{Al}_{5} \mathrm{Fe}_{2}, \mathrm{Al}_{13} \mathrm{Fe}_{4}, \mathrm{Fe}_{3} \mathrm{Al}$ and $\mathrm{FeAl}$ in it. It is shown that the formation of intermetallic compounds in coatings leads to an increase in the microhardness of steel interlayers by up to 1.7 times as compared to the initial state, while an increase in exposure from 5 to 20 minutes at one temperature is accompanied by the formation of a large amount of intermetallic compounds with a high iron content $\mathrm{Fe}_{3} \mathrm{Al}$ and $\mathrm{FeAl}$. It was found that an increase in the content of aluminum oxide and the formation of iron oxides are recorded under all heat treatment modes. Changes in the macrostructure of the coatings are recorded: as a result of low-temperature annealing at $570-620^{\circ} \mathrm{C}$, there is a significant increase in the porosity of the coatings up to $15-25 \mathrm{vol} . \%$. An increase in the annealing temperature to 720,820 , and $920^{\circ} \mathrm{C}$ is accompanied by a sequential decrease in the porosity of the coating to $15-20,7-10,6-8$ vol.\%, respectively.
\end{abstract}

Keywords: hypersonic metallization, pseudoalloys, heat treatment.

УДК: 621.793 .72

\section{Высокотемпературная термическая обработка} газотермических покрытий из псевдосплава «Fe-Al»

\author{
Григорчик А.Н., Астрашаб Е. В. ${ }^{\dagger}$, Кукареко В.А., \\ Белоцерковский М. А., Сосновский А.В. \\ Объединенный институт машиностроения НАН Беларуси, Минск, 220072, Республика Беларусь
}

\begin{abstract}
Исследованы структурно-фазовое состояние и дюрометрические характеристики газотермических покрытий из псевдосплава «Fe-Al» в исходном состоянии и после термической обработки, заключающейся в нагреве образцов покрытия до температур 570, 620, 720, 820 и $920^{\circ} \mathrm{C}$, с последующей выдержкой в течение 5, 10 и 20 минут и охлаждении на воздухе. Фазовый состав «Fe-Al» покрытия, напыленного методом высокоскоростной металлизации, в исходном состоянии включает в себя а-Fe, $\mathrm{Al}, \mathrm{Al}_{2} \mathrm{O}_{3}$ и $\mathrm{FeO}$. Твердость покрытия составляет $220 \mathrm{HV} 10$, а микротвердость стальных прослоек - $350 \mathrm{HV} 0.025$. Термическая обработка покрытия в интервале температур 570 - $920^{\circ} \mathrm{C}$ и временем выдержки 5-20 минут приводит к образованию в нем, упрочняющих интерметаллидных фаз $\mathrm{Al}_{5} \mathrm{Fe}_{2}, \mathrm{Al}_{13} \mathrm{Fe}_{4}, \mathrm{Fe}_{3} \mathrm{Al}$ и FeAl. Образование интерметаллидных соединений в покрытиях приводит к увеличению микротвердости стальных прослоек до 1.7 раза по сравнению с исходным состоянием, при этом увеличение выдержки с 5 до 20 минут, при одной температуре, сопровождается образованием большого количества интерметаллидов с высоким содержанием железа $\mathrm{Fe}_{3} \mathrm{Al}$ и FeAl. Установлено, что при всех режимах термической обработки регистрируется возрастание содержания оксида алюминия и образование оксидов железа. Регистрируются изменения в макроструктуре покрытий: в результате низкотемпературного отжига при $570-620^{\circ} \mathrm{C}$ происходит существенное возрастание пористости покрытий до $15-25$ об.\%. Увеличение температуры отжига до 720,820 и $920^{\circ} \mathrm{C}$ сопровождается последовательным снижением пористости покрытия до 15 - 20, 7-10, 6 - 8 об.\%, соответственно.
\end{abstract}

Ключевые слова: высокоскоростная металлизация, псевдосплавы, термическая обработка. 


\section{1. Введение}

В последнее время все большую популярность приобретают сплавы на основе системы железо-алюминий. Возрастающий интерес к этим материалам, обусловлен, в первую очередь, их уникальными физико-механическими характеристиками. В частности, для материалов и покрытий, содержащих интерметаллидное соединение $\mathrm{Fe}_{3} \mathrm{Al}$, характерна повышенная жаростойкость и коррозионностойкость [1-3]. Кроме этого выделение в материалах интерметаллидных частиц $\mathrm{FeAl}_{3}\left(\mathrm{Fe}_{4} \mathrm{Al}_{13}\right), \mathrm{FeAl}_{2}, \mathrm{Fe}_{2} \mathrm{Al}_{7}, \mathrm{Fe}_{2} \mathrm{Al}_{5}$ приводит к существенному увеличению прочностных свойств сплавов, так как микротвердость указанных фаз составляет $\approx 10$ ГПа [1]. Область применения сплавов, содержащих интерметаллиды системы $\mathrm{Fe}-\mathrm{Al}$, достаточно широка и, наряду с нанесением защитных слоев, покрытия также используются для восстановления изношенных деталей машин.

Традиционно используемые методы получения покрытий, содержащих интерметаллиды системы $\mathrm{Fe}-\mathrm{Al}$, как например, изостатическое прессование и спекание в вакууме, а также самораспространяющийся высокотемпературный синтез и плазменное напыление, являются дорогостоящими технологическими операциями, накладывающими существенные ограничения на область использования данных материалов [1-7]. В связи с этим, применение экономичных и высокопроизводительных способов синтезирования $\mathrm{Fe}-\mathrm{Al}$ сплавов, позволяющих получать покрытия, содержащие интерметаллиды системы Fe-Al, является актуальной задачей. Одним из перспективных методов получения таких покрытий является высокоскоростная металлизация проволочных материалов из железных и алюминиевых сплавов с последующей термической обработкой полученного покрытия. В частности, в работе [8] показано, что отжиг газотермического покрытия из псевдосплава «Fe-Al» в температурном интервале $510-550^{\circ} \mathrm{C}$ в течение 1 часа приводит выделению в нем интерметаллидных фаз, повышающих физико-механические характеристики покрытия. Вместе с тем, высокотемпературная выдержка газотермических покрытий сопровождается возрастанием их пористости, что негативно сказывается на прочностных и триботехнических свойствах покрытий. В связи с этим, представляло интерес исследовать влияние высокотемпературной термической обработки (ТО) в широком диапазоне температур на структурнофазовое состояние и дюрометрические свойства газотермических покрытий из псевдосплава «Fe-Al».

\section{2. Изготовление образцов и методики исследований}

Напыление газотермического покрытия из псевдосплава «Fe-Al» выполнялось методом высокоскоростной металлизации с использованием установки АДМ-10 [9]. Композиционное покрытие из проволок стали 08Г2С и алюминиевого сплава АК-12, напылялось на пластину $(80 \times 80 \times 5$ мм), изготовленную из стали 20 . Химический состав исходных проволок и напыленного псевдосплава определялся на приборе Epsilon 1 с методическим программным обеспечением компании PANalytical и представлен в Табл. 1.

Исследования структурно-фазового состояния покрытия из псевдосплава проводилось в исходном состоянии (после напыления), а также после термической обработки, заключающейся в нагреве образцов покрытия до температур $570,620,720,820$ и $920^{\circ} \mathrm{C}$, с последующей выдержкой в течение 5,10 и 20 минут и охлаждении на воздухе.

Металлографические исследования газотермических покрытий проводились на оптическом микроскопе АЛЬТАМИ МЕТ 1МТ. Исследование фазового состояния газотермических покрытий, проводилось на дифрактометре ДРОН-3.0 в монохроматизированном кобальтовом $\left(\mathrm{CoK}_{\alpha}\right)$ излучении при напряжении 28 кВ и анодном токе 14 мА. Расшифровка рентгенограмм осуществлялось при помощи программного обеспечения Crystallographica Search-Match c картотекой PDF-2. Измерения твердости и микротвердости по Виккерсу проводились на твердомере DuraScan 20 при нагрузке на индентор $P=10$ кг и 25 г.

\section{3. Результаты исследований и их обсуждение}

В результате совместного газотермического напыления алюминиевой и стальной проволок формируется плотное покрытие из псевдосплава «Fe-Al», состоящее из тонких слоев железа, алюминия, а также сплавленных железо-алюминиевых частиц (Рис. 1а). Между отдельными слоями покрытия, располагаются тонкие прослойки оксидов алюминия и железа. В исходном состоянии покрытие включает $\alpha-\mathrm{Fe}, \mathrm{Al}, \mathrm{Al}_{2} \mathrm{O}_{3}$ и $\mathrm{FeO}$. Необходимо отметить, что в напыленных покрытиях практически не регистрируются оксиды железа.

Низкое содержание оксидов железа в напыленном железо-алюминиевом псевдосплаве связано с предотвращением окисления частиц железа за счет их обволакивания легкоплавким алюминием в процессе метал-

Табл. 1. Химический состав исходных материалов, использовавшихся для напыления и псевдосплава «Fe-Al».

Table 1. Chemical composition of materials used for spraying falsely alloys "Fe-Al".

\begin{tabular}{|c|c|c|c|c|c|c|c|c|}
\hline \multirow{2}{*}{$\begin{array}{c}\text { Материал } \\
\text { Material }\end{array}$} & \multicolumn{7}{|c|}{ Содержание элемента, масс.\% / Content of a chemical element, wt.\% } \\
\cline { 2 - 8 } & $\mathrm{Al}$ & $\mathrm{Si}$ & $\mathrm{S}$ & $\mathrm{Cr}$ & $\mathrm{Mn}$ & $\mathrm{V}$ & $\mathrm{Cu}$ & $\mathrm{Fe}$ \\
\hline $\begin{array}{c}\text { Проволока 08Г2C } \\
\text { Wire 08Mn2Si }\end{array}$ & - & 0.76 & 0.04 & 0.10 & 2.01 & - & 0.11 & $\begin{array}{c}\text { Oснова } \\
\text { Basis }\end{array}$ \\
\hline $\begin{array}{c}\text { Проволока AK-12 } \\
\text { Wire AlSi-12 }\end{array}$ & $\begin{array}{c}\text { Основа } \\
\text { Ваsis }\end{array}$ & 11.8 & - & 0.10 & 0.48 & 0.01 & 0.56 & 1.38 \\
\hline $\begin{array}{c}\text { Покрытие «Fe-Al» } \\
\text { Соating "Fe-Al” }\end{array}$ & 33.61 & 4.12 & 0.01 & 0.02 & 0.86 & 0.01 & 0.06 & $\begin{array}{c}\text { Oснова } \\
\text { Basis }\end{array}$ \\
\hline
\end{tabular}




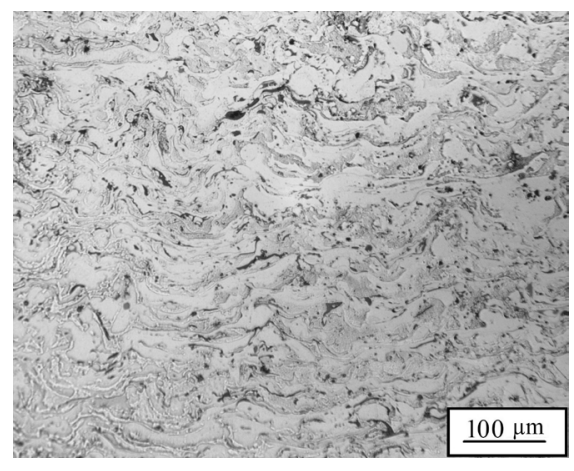

a

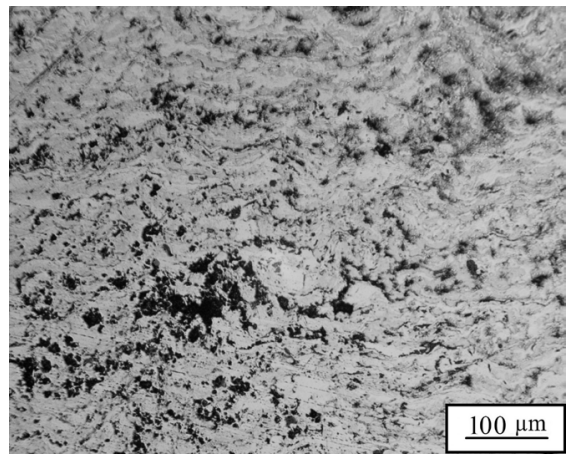

d

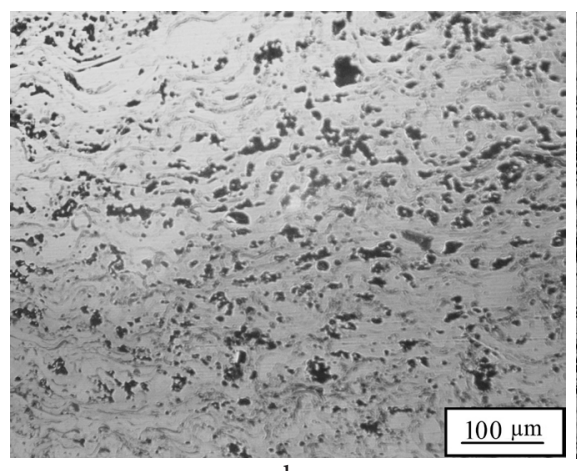

b

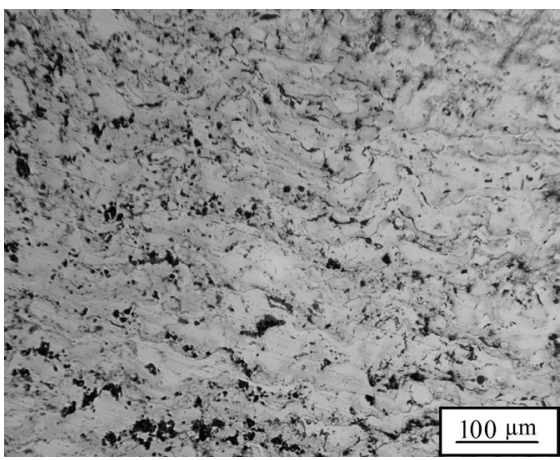

e

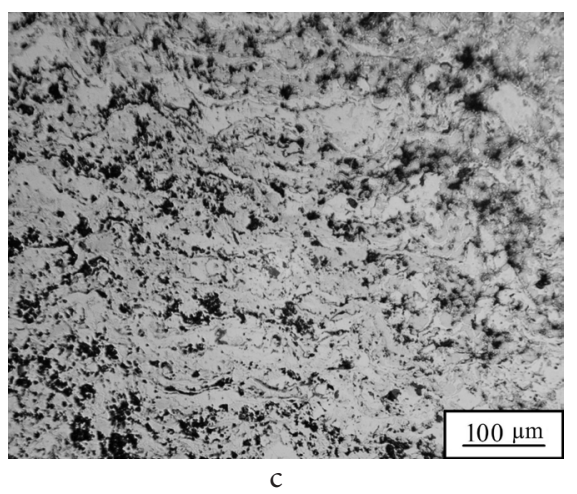

C

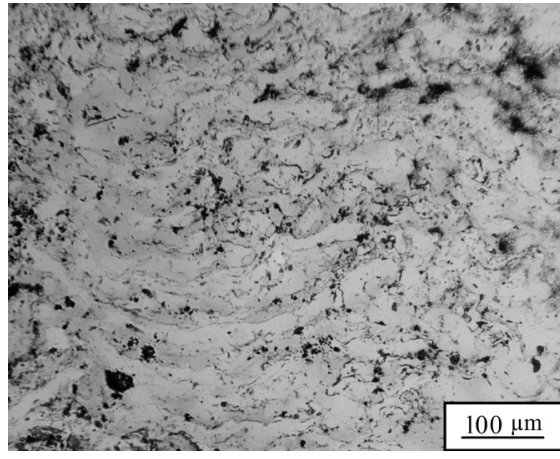

f

Pис. 1. (Color online) Характерные микроструктуры газотермических покрытий из псевдосплава «Fe-Al» в исходном состоянии (a) и после термической обработки (b, c, d, e, f) в течение 10 минут при температурах 570, 620, 720, 820 и $920^{\circ} \mathrm{C}$, соответственно.

Fig. 1. (Color online) Typical microstructures of hypersonic metallization coatings from falsely alloys «Fe-Al» in the initial state (a) and after heat treatment (b, c, d, e, f) for 10 minutes at temperatures of $570,620,720,820$ and $920^{\circ} \mathrm{C}$, respectively.

лизации, а также с восстановлением оксидов железа алюминием. При этом образование тонкой и плотной пленки оксида $\mathrm{Al}_{2} \mathrm{O}_{3}$ на поверхности расплавленных алюминиевых и железных частиц защищает их от окисления. Кратковременная термическая обработка « $\mathrm{Fe}-\mathrm{Al} »$ покрытия при $570-920^{\circ} \mathrm{C}$ приводит к существенным изменениям в его структурно-фазовом состоянии. В частности, в подвергнутых отжигу покрытиях исчезает структурно свободный алюминий и образуются интерметаллидные фазы $\mathrm{Al}_{5} \mathrm{Fe}_{2}, \mathrm{Al}_{13} \mathrm{Fe}_{4}, \mathrm{Fe}_{3} \mathrm{Al}, \mathrm{FeAl}$, a также небольшое количество оксида $\mathrm{Fe}_{3} \mathrm{O}_{4}$. Специфические изменения регистрируются также и в макроструктуре покрытий. В частности, в результате низкотемпературного отжига при $570-620^{\circ} \mathrm{C}$ происходит существенное возрастание пористости покрытий до $15-25$ об.\% (Табл. 2). Увеличение температуры отжига до 720,820 и $920^{\circ} \mathrm{C}$ сопровождается последовательным снижением пористости покрытия до 15-20, 7-10, 6-8 об.\%, соответственно (Табл. 2). Резкое увеличение пористости покрытий в результате отжига при $570-620^{\circ} \mathrm{C}$ связано с протеканием в них диффузионных процессов, описываемых механизмами Френкеля и Киркендалла [10,11]. Так, например, в случае отжига при $570^{\circ} \mathrm{C}$, диффузионная подвижность атомов легкоплавкого алюминия достаточно высока по сравнению с диффузионной подвижностью атомов железа, что приводит к преимущественному переносу атомов алюминия в железные прослойки и формированию в них интерметаллидных слоев. При этом обеспечивающие диффузию $\mathrm{Al}$ вакансии концентрируются в алюминиевых прослойках и конденсируясь на межслойных границах формируют вакансионные поры [10-13]. При температурах отжига $720-920^{\circ} \mathrm{C}$, превышающих температуру плавления алюминия, происходит взаимный диффузионный перенос атомов железа в алюминий и атомов алюминия в железо с образованием интерметаллидов. При этом, накопления вакансий в жидком алюминии не происходит и пористость покрытия понижается. Вместе с тем, особенности диффузионных процессов, происходящих в $\mathrm{Fe}-\mathrm{Al}$ покрытиях при высоких температурах отжига, требуют дополнительных прецизионных исследований. Также, повышенные температуры отжига (превышающие температуру плавления алюминия) приводят к ускоренному образованию твердых интерметаллидных фаз $\mathrm{Al}_{5} \mathrm{Fe}_{2}, \mathrm{Al}_{13} \mathrm{Fe}_{4}, \mathrm{Fe}_{3} \mathrm{Al}$, $\mathrm{FeAl}$ и твердого раствора алюминия в железе. О формировании твердого раствора в фазовом составе покрытий свидетельствуют повышенные значения параметра кристаллической решетки $\alpha$-Fe (Табл. 2) существенно превышающие соответствующее значение параметра кристаллической решетки $\alpha-\mathrm{Fe}$ для покрытия стали 08Г2С $(a=0.28665$ нм) [8].

Фазовый состав и дюрометрические свойства газотермических покрытий из псевдосплава «Fe-Al» после термической обработки представлены в Табл. 3. Как уже отмечалось, в результате высокотемпературной термической обработки в покрытиях из псевдосплава «Fe-Al» происходит образование интерметаллидных фаз (Табл. 3). При этом в случае относительно малых продолжительностей выдержки (5-10 мин) при $570-820^{\circ} \mathrm{C}$ в покрытиях преимущественно образуются интерметаллидные фазы обогащенные алюминием $\left(\mathrm{Al}_{13} \mathrm{Fe}_{4}, \mathrm{Al}_{5} \mathrm{Fe}_{2}\right)$. 
Табл. 2. Пористость и параметр кристаллической решетки $\alpha$-Fe псевдосплава «Fe-Al» после напыления и после термической обработки в течение 10 минут.

Table 2. Porosity and lattice parameter of the a-Fe from falsely alloys "Fe-Al" after spraying and after heat treatment for 10 minutes.

\begin{tabular}{|c|c|c|}
\hline $\begin{array}{c}\text { Обработка покрытия } \\
\text { Treatment of coating }\end{array}$ & $\begin{array}{c}\text { Пористость, об.\% } \\
\text { Porosity, vol.\% }\end{array}$ & $\begin{array}{c}\text { Параметр кристаллической решетки }(a) \alpha \text {-Fе, нм } \\
\text { Crystal lattice parameter }(a) \text { of } \alpha \text {-Fe, nm }\end{array}$ \\
\hline $\begin{array}{c}\text { Исходное состояние } \\
\text { The initial state }\end{array}$ & $3-5$ & 0.28753 \\
\hline $\begin{array}{c}\text { TO при } 570^{\circ} \mathrm{C} \\
\text { Heat treatment at } 570^{\circ} \mathrm{C}\end{array}$ & $15-20$ & 0.28754 \\
\hline $\begin{array}{c}\text { TO при } 620^{\circ} \mathrm{C} \\
\text { Heat treatment at } 620^{\circ} \mathrm{C}\end{array}$ & $20-25$ & 0.28759 \\
\hline $\begin{array}{c}\text { TO при } 720^{\circ} \mathrm{C} \\
\text { Heat treatment at } 720^{\circ} \mathrm{C}\end{array}$ & $15-20$ & 0.28766 \\
\hline $\begin{array}{c}\text { TO при } 820^{\circ} \mathrm{C} \\
\text { Heat treatment at } 820^{\circ} \mathrm{C}\end{array}$ & $7-10$ & 0.28791 \\
\hline $\begin{array}{c}\text { TO при } 920^{\circ} \mathrm{C} \\
\text { Heat treatment at } 920^{\circ} \mathrm{C}\end{array}$ & $6-8$ & 0.28821 \\
\hline
\end{tabular}

Табл. 3. Фазовый состав, микротвердость и твердость псевдосплава «Fe-Al» после напыления и после термической обработки. Table 3. Phase composition, microhardness and hardness of falsely alloys "Fe-Al" after spraying and after heat treatment.

\begin{tabular}{|c|c|c|c|}
\hline $\begin{array}{l}\text { Обработка покрытия } \\
\text { Treatment of coating }\end{array}$ & $\begin{array}{l}\text { Фазовый состав } \\
\text { Phase composition }\end{array}$ & HV0.025 & HV10 \\
\hline $\begin{array}{l}\text { Исходное состояние } \\
\text { The initial state }\end{array}$ & $\alpha-\mathrm{Fe}, \mathrm{Al}, \mathrm{Al}_{2} \mathrm{O}_{3}, \mathrm{FeO}$ & 350 & 220 \\
\hline $\begin{array}{l}\text { Нагрев до } 570^{\circ} \mathrm{C} \text {, выдержка } 5 \text { мин } \\
\text { Heating up to } 570^{\circ} \mathrm{C} \text {, exposure } 5 \mathrm{~min}\end{array}$ & $\alpha-\mathrm{Fe}, \mathrm{Al}_{5} \mathrm{Fe}_{2}, \mathrm{Al}_{13} \mathrm{Fe}_{4}, \mathrm{Fe}_{3} \mathrm{Al}, \mathrm{FeAl}, \mathrm{Fe}_{3} \mathrm{O}_{4}, \mathrm{Al}_{2} \mathrm{O}_{3}, \mathrm{FeO}$ & 420 & 195 \\
\hline $\begin{array}{l}\text { Нагрев до } 570^{\circ} \mathrm{C} \text {, выдержка } 10 \text { мин } \\
\text { Heating up to } 570^{\circ} \mathrm{C} \text {, exposure } 10 \mathrm{~min}\end{array}$ & $\alpha-\mathrm{Fe}, \mathrm{Al}_{5} \mathrm{Fe}_{2}, \mathrm{Al}_{13} \mathrm{Fe}_{4}, \mathrm{Fe}_{3} \mathrm{Al}, \mathrm{FeAl}, \mathrm{Fe}_{3} \mathrm{O}_{4}, \mathrm{Al}_{2} \mathrm{O}_{3}, \mathrm{FeO}$ & 430 & 200 \\
\hline $\begin{array}{l}\text { Нагрев до } 570^{\circ} \mathrm{C} \text {, выдержка } 20 \text { мин } \\
\text { Heating up to } 570^{\circ} \mathrm{C} \text {, exposure } 20 \mathrm{~min}\end{array}$ & $\alpha-\mathrm{Fe}, \mathrm{Al}_{5} \mathrm{Fe}_{2}, \mathrm{Al}_{13} \mathrm{Fe}_{4}, \mathrm{Fe}_{3} \mathrm{Al}, \mathrm{FeAl}, \mathrm{Fe}_{3} \mathrm{O}_{4}, \mathrm{Al}_{2} \mathrm{O}_{3}, \mathrm{FeO}$ & 430 & 200 \\
\hline $\begin{array}{l}\text { Нагрев до } 620^{\circ} \mathrm{C} \text {, выдержка } 5 \text { мин } \\
\text { Heating up to } 620^{\circ} \mathrm{C} \text {, exposure } 5 \mathrm{~min}\end{array}$ & a-Fe, $\mathrm{Al}_{5} \mathrm{Fe}_{2}, \mathrm{Al}_{13} \mathrm{Fe}_{4}, \mathrm{Fe}_{3} \mathrm{Al}, \mathrm{FeAl}, \mathrm{Fe}_{3} \mathrm{O}_{4}, \mathrm{Al}_{2} \mathrm{O}_{3}, \mathrm{FeO}$ & 600 & 190 \\
\hline $\begin{array}{l}\text { Нагрев до } 620^{\circ} \mathrm{C} \text {, выдержка } 10 \text { мин } \\
\text { Heating up to } 620^{\circ} \mathrm{C} \text {, exposure } 10 \mathrm{~min}\end{array}$ & $\alpha-\mathrm{Fe}, \mathrm{Al}_{13} \mathrm{Fe}_{4}, \mathrm{Al}_{5} \mathrm{Fe}_{2}, \mathrm{Fe}_{3} \mathrm{Al}, \mathrm{FeAl}, \mathrm{Fe}_{3} \mathrm{O}_{4}, \mathrm{Al}_{2} \mathrm{O}_{3}, \mathrm{FeO}$ & 570 & 185 \\
\hline $\begin{array}{l}\text { Нагрев до } 620^{\circ} \mathrm{C} \text {, выдержка } 20 \text { мин } \\
\text { Heating up to } 620^{\circ} \mathrm{C} \text {, exposure } 20 \mathrm{~min}\end{array}$ & $\alpha-\mathrm{Fe}, \mathrm{Al}_{13} \mathrm{Fe}_{4}, \mathrm{Fe}_{3} \mathrm{Al}, \mathrm{FeAl}, \mathrm{Al}_{5} \mathrm{Fe}_{2}, \mathrm{Fe}_{3} \mathrm{O}_{4}, \mathrm{Al}_{2} \mathrm{O}_{3}, \mathrm{FeO}$ & 475 & 185 \\
\hline $\begin{array}{l}\text { Нагрев до } 720^{\circ} \mathrm{C} \text {, выдержка } 5 \text { мин } \\
\text { Heating up to } 720^{\circ} \mathrm{C} \text {, exposure } 5 \mathrm{~min}\end{array}$ & $\alpha-\mathrm{Fe}, \mathrm{Al}_{13} \mathrm{Fe}_{4}, \mathrm{Al}_{5} \mathrm{Fe}_{2}, \mathrm{FeAl}, \mathrm{Fe}_{3} \mathrm{Al}, \mathrm{Fe}_{3} \mathrm{O}_{4}, \mathrm{Al}_{2} \mathrm{O}_{3}, \mathrm{FeO}$ & 570 & 195 \\
\hline $\begin{array}{l}\text { Нагрев до } 720^{\circ} \mathrm{C} \text {, выдержка } 10 \text { мин } \\
\text { Heating up to } 720^{\circ} \mathrm{C} \text {, exposure } 10 \mathrm{~min}\end{array}$ & a-Fe, $\mathrm{Al}_{13} \mathrm{Fe}_{4}, \mathrm{FeAl}, \mathrm{Fe}_{3} \mathrm{Al}, \mathrm{Al}_{5} \mathrm{Fe}_{2}, \mathrm{Fe}_{3} \mathrm{O}_{4}, \mathrm{Al}_{2} \mathrm{O}_{3}, \mathrm{FeO}$ & 520 & 195 \\
\hline $\begin{array}{l}\text { Нагрев до } 720^{\circ} \mathrm{C} \text {, выдержка } 20 \mathrm{мин} \\
\text { Heating up to } 720^{\circ} \mathrm{C} \text {, exposure } 20 \mathrm{~min}\end{array}$ & a-Fe, $\mathrm{Al}_{13} \mathrm{Fe}_{4}, \mathrm{FeAl}, \mathrm{Fe}_{3} \mathrm{Al}, \mathrm{Al}_{5} \mathrm{Fe}_{2}, \mathrm{Fe}_{3} \mathrm{O}_{4}, \mathrm{Al}_{2} \mathrm{O}_{3}, \mathrm{FeO}$ & 460 & 195 \\
\hline $\begin{array}{l}\text { Нагрев до } 820^{\circ} \mathrm{C} \text {, выдержка } 5 \text { мин } \\
\text { Heating up to } 820^{\circ} \mathrm{C} \text {, exposure } 5 \text { min }\end{array}$ & a-Fe, $\mathrm{Al}_{13} \mathrm{Fe}_{4}, \mathrm{FeAl}, \mathrm{Fe}_{3} \mathrm{Al}, \mathrm{Al}_{5} \mathrm{Fe}_{2}, \mathrm{Fe}_{3} \mathrm{O}_{4}, \mathrm{Al}_{2} \mathrm{O}_{3}, \mathrm{FeO}$ & 510 & 195 \\
\hline $\begin{array}{l}\text { Нагрев до } 820^{\circ} \mathrm{C} \text {, выдержка } 10 \text { мин } \\
\text { Heating up to } 820^{\circ} \mathrm{C} \text {, exposure } 10 \mathrm{~min}\end{array}$ & a-Fe, $\mathrm{Al}_{13} \mathrm{Fe}_{4}, \mathrm{FeAl}, \mathrm{Fe}_{3} \mathrm{Al}, \mathrm{Fe}_{3} \mathrm{O}_{4}, \mathrm{Al}_{2} \mathrm{O}_{3}, \mathrm{FeO}$ & 485 & 200 \\
\hline $\begin{array}{l}\text { Нагрев до } 820^{\circ} \mathrm{C} \text {, выдержка } 20 \mathrm{мин} \\
\text { Heating up to } 820^{\circ} \mathrm{C} \text {, exposure } 20 \mathrm{~min}\end{array}$ & $\alpha-\mathrm{Fe}, \mathrm{Fe}_{3} \mathrm{Al}, \mathrm{Al}_{13} \mathrm{Fe}_{4}, \mathrm{FeAl}, \mathrm{Fe}_{3} \mathrm{O}_{4}, \mathrm{Al}_{2} \mathrm{O}_{3}, \mathrm{FeO}$ & 460 & 200 \\
\hline $\begin{array}{l}\text { Нагрев до } 920^{\circ} \mathrm{C} \text {, выдержка } 5 \text { мин } \\
\text { Heating up to } 920^{\circ} \mathrm{C} \text {, exposure } 5 \mathrm{~min}\end{array}$ & $\alpha-\mathrm{Fe}, \mathrm{Fe}_{3} \mathrm{Al}, \mathrm{FeAl}, \mathrm{Al}_{13} \mathrm{Fe}_{4}, \mathrm{Al}_{5} \mathrm{Fe}_{2}, \mathrm{Fe}_{3} \mathrm{O}_{4}, \mathrm{Al}_{2} \mathrm{O}_{3}, \mathrm{FeO}$ & 425 & 200 \\
\hline $\begin{array}{l}\text { Нагрев до } 920^{\circ} \mathrm{C} \text {, выдержка } 10 \text { мин } \\
\text { Heating up to } 920^{\circ} \mathrm{C} \text {, exposure } 10 \mathrm{~min}\end{array}$ & $\alpha-\mathrm{Fe}, \mathrm{Fe}_{3} \mathrm{Al}, \mathrm{FeAl}, \mathrm{Al}_{13} \mathrm{Fe}_{4}, \mathrm{Al}_{5} \mathrm{Fe}_{2}, \mathrm{Fe}_{3} \mathrm{O}_{4}, \mathrm{Al}_{2} \mathrm{O}_{3}, \mathrm{FeO}$ & 440 & 200 \\
\hline $\begin{array}{l}\text { Нагрев до } 920^{\circ} \mathrm{C} \text {, выдержка } 20 \mathrm{мин} \\
\text { Heating up to } 920^{\circ} \mathrm{C} \text {, exposure } 20 \mathrm{~min}\end{array}$ & a-Fe, $\mathrm{Fe}_{3} \mathrm{Al}, \mathrm{FeAl}, \mathrm{Al}_{13} \mathrm{Fe}_{4}, \mathrm{Al}_{5} \mathrm{Fe}_{2}, \mathrm{Fe}_{3} \mathrm{O}_{4}, \mathrm{Al}_{2} \mathrm{O}_{3}, \mathrm{FeO}$ & 445 & 200 \\
\hline
\end{tabular}


Кроме этого, при указанных параметрах ТО образуются также в небольшом количестве интерметаллиды содержащие повышенное количество железа $\mathrm{Fe}_{3} \mathrm{Al}$ и $\mathrm{FeAl}$ (Табл. 3). Увеличение температуры термической обработки покрытий из псевдосплава до $920^{\circ} \mathrm{C}$, а также возрастание продолжительности выдержки при температурах $570,620,720$ и $820^{\circ} \mathrm{C}$ до 20 минут приводит к уменьшению в них количества фаз $\mathrm{Al}_{5} \mathrm{Fe}_{2}$ и $\mathrm{Al}_{13} \mathrm{Fe}_{4}$ и увеличению доли интерметаллидов $\mathrm{Fe}_{3} \mathrm{Al}$ и $\mathrm{FeAl}$ (Табл. 3). Необходимо отметить, что при всех режимах термической обработки регистрируется возрастание содержания оксида алюминия и образование оксидов железа.

Твердость покрытия из псевдосплава «Fe-Al» в исходном состоянии составляет 220 HV10, а микротвердость стальных прослоек $350 \mathrm{HV} 0.025$ (Табл. 3). Образование в покрытиях, в относительно большом количестве, обогащенных алюминием интерметаллидных фаз $\mathrm{Al}_{5} \mathrm{Fe}_{2}$ и $\mathrm{Al}_{13} \mathrm{Fe}_{4}$ при температурах термической обработки $570,620,720$ и $820^{\circ} \mathrm{C}(5-10$ минут) приводит к существенному возрастанию микротвердости стальных прослоек (Табл. 3). В частности, значения микротвердости стальных прослоек возрастают в $\approx 1.4-1.7$ раз по сравнению с исходным нетермообработанным состоянием (Табл. 3). Увеличение температуры термической обработки до $920^{\circ} \mathrm{C}$ и времени выдержки до 20 минут при температурах 620, 720 и $820^{\circ} \mathrm{C}$ приводит к возрастанию микротвердости стальных прослоек в $1.20-1.35$ раза по сравнению с исходным состоянием (Табл. 3). Незначительное понижение уровня значений микротвердости $\mathrm{Fe}-\mathrm{Al}$ прослоек после отжига при $920^{\circ} \mathrm{C}$ связано с увеличением содержания в них интерметаллидных фаз $\mathrm{FeAl}$ и $\mathrm{Fe}_{3} \mathrm{Al}$, характеризующихся относительно пониженными дюрометрическими свойствами [14]. Необходимо отметить, что макротвердость всех покрытий из псевдосплава «Fe-Al» после термической обработки ниже чем у покрытия в исходном состоянии (Табл. 3). Снижение твердости покрытий после их термической обработки связано с увеличением пористости, а также содержания оксидов (Табл. 2). В частности, при максимальных значениях пористости в 20 - 25 об.\% (Табл. 2) твердость псевдосплава снизилась до 180 HV10 (Табл. 3).

Таким образом, высокотемпературная термическая обработка газотермических покрытий из псевдосплава

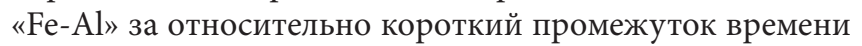
приводит к выделению в них интерметаллидных фаз, оказывающих существенное влияние на их физикомеханические свойства.

\section{4. Заключение}

Исследовано структурно-фазовое состояние и дюрометрические свойства газотермических покрытий из псевдосплава «Fe-Al» в исходном состоянии и после термической обработки, заключающейся в нагреве покрытий до температур 570, 620, 720, 820 и $920^{\circ} \mathrm{C}$, выдержке в течение 5, 10 и 20 минут и охлаждении на воздухе. Показано, что напыленное покрытие в исходном состоянии содержит $\alpha-\mathrm{Fe}, \mathrm{Al}, \mathrm{Al}_{2} \mathrm{O}_{3}$ и $\mathrm{FeO}$.
Твердость покрытия составляет 220 HV10, а микротвердость стальных прослоек - 350 HV0.025.

Установлено, что при температурах термической обработки $570-820^{\circ} \mathrm{C}$ с выдержкой до 10 минут, происходит образование интерметаллидных фаз $\mathrm{Al}_{5} \mathrm{Fe}_{2}$ и $\mathrm{Al}_{13} \mathrm{Fe}_{4}$, приводящие к возрастанию микротвердости в $\approx 1.4-1.7$ раз по сравнению с исходным состоянием. Увеличение изотермической выдержки до 20 минут сопровождается образованием большого количества интерметаллидов с высоким содержанием железа $\mathrm{Fe}_{3} \mathrm{Al}$ и FeAl. Относительно низкие температуры термической обработки $\left(570,620^{\circ} \mathrm{C}\right)$ приводят к существенному возрастанию пористости покрытий до $15-25$ об.\%, что связано с высокой диффузионной подвижностью атомов алюминия, обеспечивающей формирование вакансионных пор. При высоких температурах термической обработки $720-920^{\circ} \mathrm{C}$ происходит расплавление алюминиевых прослоек покрытия и растворение в них атомов железа. В результате этого, на границах между железом и алюмосодержащими слоями происходит формирование слоев интерметаллидов. Быстрое диффузионное перемещение атомов железа в алюминиевый расплав сопровождается образованием вакансионных пор на границе между слоями.

\section{Литература/References}

1. I.A. Seliverstov, G.N. Trotsan, I.V. Smirnov, S.R. Seliverstrov. Scientific bulletin of the Kherson State Maritime Academy. 1 (10), 249 (2014). (in Russian) [И.А. Селиверстов, Г.Н. Троцан, И.В. Смирнов, С.Р. Селиверстрова. Научный вестник Херсонской государственной морской академии. 1 (10), 249 (2014).]

2. A.F. Dresvyannikov, M.E. Kolpakov. Bulletin of Kazan Technological University. 5, 7 (2010). (in Russian) [А.Ф. Дресвянников, М.Е. Колпаков. Вестник Казанского технологического университета. 5, 7 (2010).]

3. G.A. Baglyuk, A.I. Tolochin, A.V. Tolochina, V.S. Kurikhin, R.V. Yakovenko. Resursozberihayuchi tekhnolohiyi vyrobnytstva ta obrobky tyskom materialiv u mashynobuduvanni. 1, 88 (2014). (in Russian) [Г. А. Баглюк, А.И. Толочин, А.В. Толочина, В.С. Курихин, Р.В. Яковенко. Ресурсозберігаючі технології виробництва та обробки тиском матеріалів у машинобудуванні. 1, 88 (2014).]

4. V.S. Rusakov, K.K. Kadyrzhanov, E.E. Suslov, D. A. Plaksin, T. E. Turkebaev. Surface. X-ray, synchrotron and neutron research. 12, 22 (2004). (in Russian) [В.С. Русаков, К.К. Кадыржанов, Е.Е. Суслов, Д.А. Плаксин, Т.Э. Туркебаев. Поверхность. Рентгеновские, синхротронные и нейтронные исследования. 12, 22 (2004).]

5. L.M. Gurevich, D.V. Pronichev, A.F. Trudov, Yu.P. Trykov, M.D. Trunov. Bulletin of the Volgograd State Technical University. 9 (136), 17 (2014). (in Russian) [Л. М. Гуревич, Д. В. Проничев, А.Ф. Трудов, Ю.П. Трыков, М.Д. Трунов. Известия Волгоградс- 
кого государственного технического университета. 9 (136), 17 (2014).]

6. V.A. Kukareko, M.A. Belotserkovsky, A. N. Grigorchik, E. V.Astrashab. Processing with concentrated energy flows. Hardening technologies and coatings. 15 (8), 355 (2019). (in Russian) [В.А. Кукареко, М.А. Белоцерковский, A.Н. Григорчик, Е.В. Астрашаб. Обработка концентрированными потоками энергии. Упрочняющие технологии и покрытия. 15 (8), 355 (2019).]

7. V.G. Shmorgun, D.V. Pronichev, V.P. Kulevich, O. V. Slautin, N.A. Artemiev. Bulletin of the Volgograd State Technical University. 2 (225), 14 (2019). (in Russian) [В. Г. Шморгун, Д. В. Проничев, В. П. Кулевич, О.В. Слаутин, Н.А. Артемьев. Известия Волгоградского государственного технического университета. 2 (225), 14 (2019).]

8. E.V. Astrashab, A.N. Grigorchik, V.A. Kukareko, M.A. Belotserkovsky. Friction and wear. 41 (1), 12 (2020). (in Russian) [Е.В. Астрашаб, А.Н. Григорчик, В. А. Кукареко, М. А. Белоцерковский. Трение и износ. 41 (1), 12 (2020).]

9. M.A. Belotserkovsky. Technologies of activated flame spraying of antifriction coatings. Minsk, Technoprint
Unitary Enterprise (2004) 200 p. (in Russian) [M. А. Белоцерковский. Технологии активированного газопламенного напыления антифрикционных покрытий. Минск, УП «Технопринт» (2004) 200 с.]

10. M. A. Krishtal. Diffusion mechanism in iron alloys. Moscow, Metallurgiya (1972) 400 p. (in Russian) [M.А. Криштал. Механизм диффузии в железных сплавах. Москва, Металлургия (1972) 400 с.]

11. S. B. Bokshtein. Diffusion in metals. Moscow, Metallurgiya (1978) 248 p. (in Russian) [С. Б. Бокштейн. Диффузия в металлах. Москва, Металлургия (1978) 248 с.]

12. V. Zayt. Diffusion in metals. (ed. by B. I. Boltax). Moscow, Foreign Literature Publishing House (1958) 381 p. (in Russian) [В. Зайт. Диффузия в металлах. (под ред. Б.И. Болтакса). Москва, Издательство иностранной литературы (1958) 381 с.]

13. B. Bokshtein, A. Epishin, I. Svetlov, V. Esin, A. Rodin, T. Link. Functional materials. 1 (5), 162 (2007). (in Russian) [Б. Бокштейн, А. Епишин, И. Светлов, В. Есин, А. Родин, Т. Линк. Функциональные материалы. 1 (5), 162 (2007).]

14. Yu. R. Kolobov. Moscow, MISIS Publishing House. (2008) 326 p. (in Russian) [Ю.Р. Колобов. Москва, МИСиС издательский дом (2008) 326 c.] 